\title{
Role of saline infusion sonography in patients with infertility and comparison of the same with transvaginal ultrasonography
}

\author{
Sripriya Thiruvengadathan ${ }^{1}$, T.G. Sivaranjani ${ }^{2}$, Vidya Chaya ${ }^{3}$, Devi $^{4}$ \\ ${ }^{1}$ Dr. Sripriya Thiruvengadathan, DMRD, DNB, Consultant Radiologist, Dr. Kamakshi Institute of Medical Sciences and \\ Research, Pallikaranai, Chennai, ${ }^{2}$ Dr.T.G. Sivaranjani, Obstetrician and Gynoecologist, ${ }^{3}$ Dr.Vidya Chaya, Obstetrician \\ and Gynoecologist, ${ }^{4}$ Dr. Devi, Obstetrician and Gynoecologist, Chennai.
}

Address for correspondence: Dr. Sripriya Thiruvengadathan, Email: sripriya.thiruvengadathan@gmail.com

\begin{abstract}
Introduction: Transvaginal scan is considered as the baseline investigation in women with infertility. Saline infusion sonography is used to study the distended uterine cavity and provides adequate visualisation of the same. This study is performed to assess the role of SIS in women with infertility and to compare its ability in identifying endometrial pathology with that of routine transvaginal sonography. Materials and Methods: In this prospective study, we studied 20 women who attended the infertility clinic in our hospital. All were subjected to routine transvaginal scan followed by saline infusion sonography after obtaining consent for the procedure. All these 20 women also underwent diagnostic hysteroscopy for evaluation of endometrium. Results: The findings noted with transvaginal scan and SIS were analysed and compared with hysteroscopy findings. Endometrial polyp was identified in 8 patients and rest 12 were found to have normal endometrium in Transvaginal scan. 8 women were found to have polyp, 1 with synachiae and rest 11 with normal endometrial cavity during saline infusion sonography. However hysteroscopy showed polyp in 8 and synechiae in 1 . The sensitivity of SIS in identifying endometrial pathology in infertile women was better than that of TVS. Specificity remains same for both modalities. Polyps were better identified and demonstrated with SIS, however both modalities were not very efficient in identifying synachiae. Conclusion: Saline infusion sonography, being an outpatient procedure requiring no anaesthesia and cost effective, can be used confidently to study the endometrial cavity in women with infertility as base line investigation. Those in whom abnormalities identified during the study can be taken up for invasive procedure, hysteroscopy. SIS can thus be performed as a preliminary procedure before hysteroscopy.
\end{abstract}

\section{Introduction}

Transvaginal scan is considered as the baseline investigation in women with infertility. It refers to scan done via vaginal route to image the uterus and ovaries. Transvaginal scan needs no patient preparation and is highly acceptable by all patients as it is non invasive. It gives good picture of the uterine and ovarian morphology [1]. Thickness, pattern and vascularity of the endometrium are usually asessed by a transvaginal scan. Saline infusion sonography is done transvaginally after injecting sterile saline into the endometrial cavity. Saline distends the uterine cavity and provides adequate visualisation. Lesions of the endometrium stand out prominently following distension with saline. It also has an advantage of assessing the patency of the tubes.

Manuscript received: $7^{\text {th }}$ Nov 2015

Reviewed: $19^{\text {th }}$ Nov 2015

Author Corrected: $29^{\text {th }}$ Nov 2015

Accepted for Publication: $18^{\text {th }}$ Dec 2015
Hysteroscopy is an invasive procedure requiring anaesthesia to evaluate the endometrial cavity. But it has the advantage of treating the lesion, if any present in the endometrial cavity. Hysteroscopy is considered the gold standard in evaluating the endometrial lesions.

This study is performed to assess the role of SIS in women with infertility and to compare its ability in identifying endometrial pathology with that of routine transvaginal sonography.

\section{Materials and Methods}

In this prospective study, we studied 20 women who attended the infertility clinic in our hospital. We included those with normal ovulatory pattern, documented by follicular studies ie serial monitoring of the dominant follicles till rupture. Delay in conception in such patients was considered to be due to uterine 
factors. We excluded those with anovulatory cycles. All were subjected to routine transvaginal scan followed by saline infusion sonography after obtaining consent for the procedure. With the patient in dorsal position, transvaginal scan was performed using GE voluson E6 endocavity transducer. Findings were recorded and images were acquired for the study. This was followed by saline infusion sonography. With patient in lithotomy position, under aseptic precautions a $7 \mathrm{Fr}$ COOK Hysterosalphingography catheter was introduced into the uterine cavity. We preferred this catheter because it has a bulb in the tip and was inflated at the level of external os with $1 \mathrm{ml}$ saline to prevent back flow of saline from the uterine cavity. About $8 \mathrm{ml}$ of sterile saline was then injected into the catheter to get adequate distension of the endometrial cavity. Sagittal and coronal images of uterus were obtained and findings were recorded. We also did 3D reconstruction of the uterine cavity in the same sitting. Few patients complained of mild pelvic discomfort, which was taken care by analgesics. Rest tolerated the procedure well. No complications were observed during and after the study.

All these 20 women underwent diagnostic hysteroscopy and the TVS/SIS findings were correlated with the same.

\section{Results}

The findings noted with transvaginal scan and SIS were analysed and compared with hysteroscopy findings.
Endometrial polyp was identified in 8 patients and rest 12 were found to have normal endometrium in TVS. 8 women were found to have polyp, 1 with synachiae and rest 11 with normal endometrial cavity in SIS. However hysteroscopy showed polyp in 8 and synechiae in 1 . Table 1 gives details of the findings in SIS, TVS and hysteroscopy.

One woman who was reported to have a normal endometrium in TVS had a polyp in SIS and hysteroscopy. Another woman reported to have a single endometrial polyp was found to have two polyps in SIS and same was confirmed by hysteroscopy. Normal study observed in TVS and SIS in a patient was proven wrong in hysteroscopy as there were synechiae within the endometrial cavity. In another woman we reported as synachiae in SIS but was found to be normal in hysteroscopy. Also one case reported as polyp in TVS was found to be normal in SIS and hysteroscopy.

Those with positive findings were treated accordingly during the hysteroscopic procedure.

Table 2 gives the diagnostic performance of TVS and SIS. The sensitivity of SIS in identifying endometrial pathology in infertile women was better than that of TVS. Specificity remains same for both modalities. Polyps were better identified and demonstrated with SIS, however both modalities were not very efficient in identifying synachiae.

Table 1: Comparative analysis of TVS, SSG \& and Hysteroscopy

\begin{tabular}{|l|l|l|l|}
\hline S. No & TVS & SSG & Hysteroscopy \\
\hline 1 & polyp & Polyp & polyp \\
\hline 2 & polyp & Polyp & polyp \\
\hline 3 & polyp & Polyp & polyp \\
\hline 4 & normal & Normal & normal \\
\hline 5 & normal & Synechiae & normal \\
\hline 6 & 1 polyp & 2 polyps & 2 polyps \\
\hline 7 & polyp & Polyp & polyp \\
\hline 8 & normal & Polyp & polyp \\
\hline 9 & normal & Normal & normal \\
\hline 10 & normal & Normal & normal \\
\hline 11 & normal & Normal & normal \\
\hline 12 & polyp & Polyp & polyp \\
\hline 13 & normal & Normal & normal \\
\hline 14 & normal & Normal & normal \\
\hline
\end{tabular}




\begin{tabular}{|l|l|l|l|}
\hline 15 & normal & Normal & normal \\
\hline 16 & normal & Normal & normal \\
\hline 17 & polyp & Polyp & polyp \\
\hline 18 & normal & Normal & normal \\
\hline 19 & polyp & Normal & normal \\
\hline 20 & normal & Normal & synechiae \\
\hline
\end{tabular}

Table 2: Diagnostic performance of SIS and TVS:

\begin{tabular}{|l|l|l|l|l|}
\hline Test & Sensitivity & Specificity & $\begin{array}{l}\text { Positive predictive } \\
\text { value }\end{array}$ & $\begin{array}{l}\text { Negative predictive } \\
\text { value }\end{array}$ \\
\hline SIS & $88.89 \%$ & $90.91 \%$ & $88.89 \%$ & $90.91 \%$ \\
\hline TVS & $77.78 \%$ & $90.91 \%$ & $87.50 \%$ & $83.33 \%$ \\
\hline
\end{tabular}

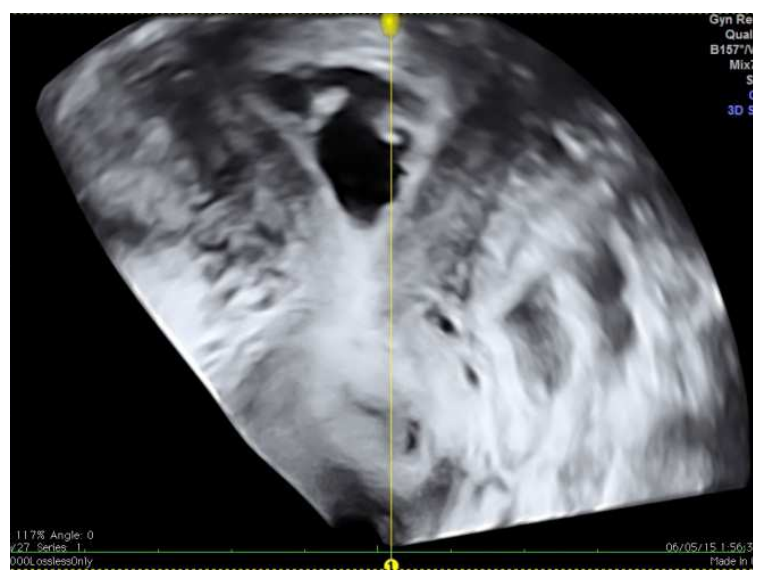

Fig 1: 3D uterus with synachiae

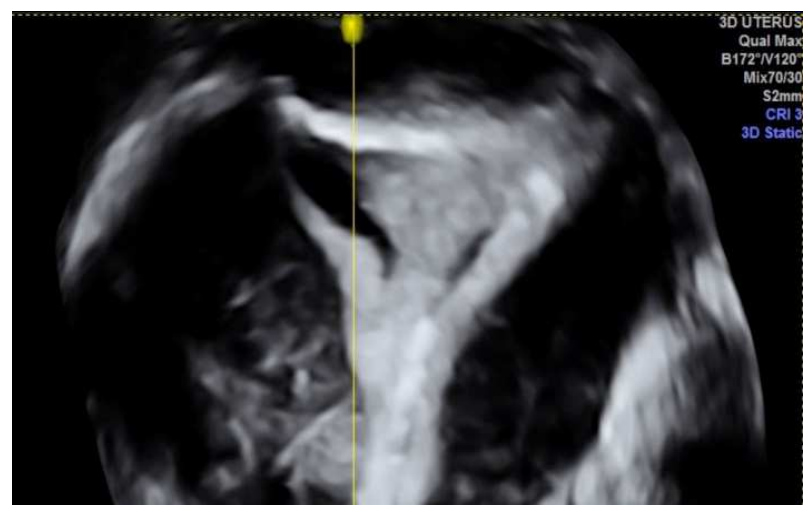

Fig 3 : 3D uterus with endometrial polyp.

\section{Discussion}

A good endometrium is required for implantation of the fertilised ovum. Presence of an endometrial polyp, submucous fibroid or synechiae results in subfertility. Hence identification of these pathologies is very essential in infertile women.

Transvaginal sonography is believed to be the basic investigation in infertile women. Sagittal, coronal and 3

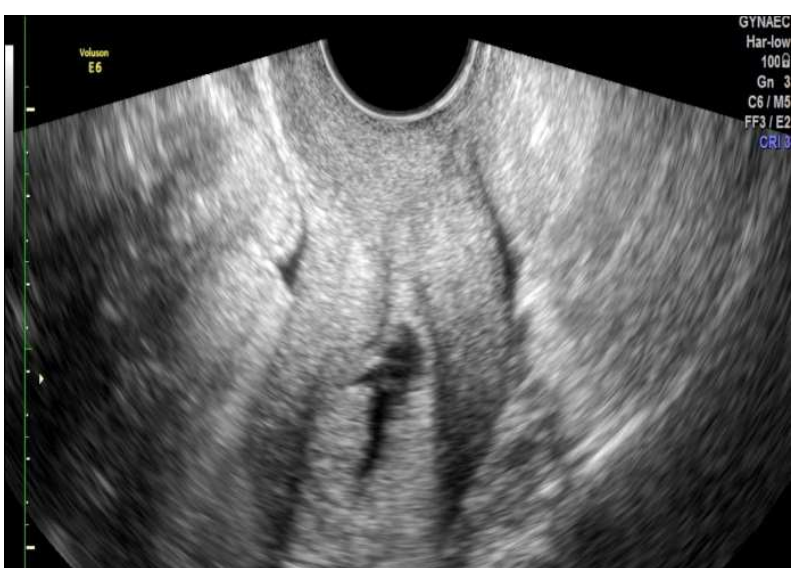

Fig 2: distended uterine cavity with polyp

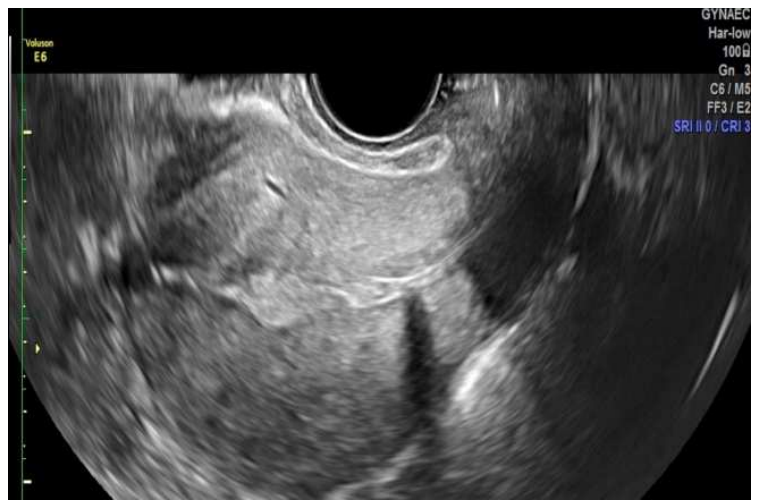

Fig 4: TVS showing endometrial polyp

D imaging of the uterus helps in studying the endometrium. It also helps to study the endometrial thickness, pattern and vascularity [1].

Saline infusion sonography is recently being practised in order to assess the endometrium. Adequate distension of the endometrial cavity depicts intracavity lesions better than the routine TVS. The lesions stand out prominently within the distended endometrial cavity. A 
$3 \mathrm{D}$ reconstruction of the uterus along with tomographic imaging during the SIS study is very helpful in knowing the precise location of the lesion and help as a guide to the surgeon in treating the same hysteroscopically [2]. A normal endometrial cavity in saline infusion sonography avoids diagnostic hysteroscopy in these women. SIS can be done as an out patient procedure and requires no anaesthesia. Most of the women are able to co operate through out the procedure. SIS is considered a better modality for imaging of endometrial and subendometrial lesions [3].

Reddi Rani P et al, has studied 52 cases with abnormal uterine bleeding and concluded that SIS is useful in demonstrating submucus fibroids and polyps [4]. Nanda $\mathrm{S}$ et al says saline infusion sono hysterography is more accurate in diagnosing submucous fibroids and endometrial polyps in the patients of abnormal uterine bleeding than is TVS. The author also suggests that SIS should be reserved for patients with centrally located fibroids as they me be submucus [5].

Differentiation of an endometrial polyp from a submucus fibroid is possible with saline infusion sonography. The polyp is often hyperechoic while a fibroid is hypoechoic in most of the cases.

Polyps typically have a round shape with smooth margins. Presence of a vascular pedicle is often identified in polyps. The myometrial endometrial interface is preserved in case of polyps while it is lost or poorly defined in case of submucus fibroids. SIS helps in identifying the vascular pedicle and clearly depicts the endo-myometrial interface [6].

Mohammad aslam et al has studied the role of saline infusion sonography in women with abnormal uterine bleeding and concluded that SIS is useful in identifying focal endometrial lesion. He has also suggested that SIS is very useful in selection of patients for hysteroscopy guided procedures and that SIS should be used as an initial investigation in women with abnormal uterine bleeding. The author also says that exact location of the submucus myoma can be identified by SIS and hence it could be a good guidance for the surgeon during hysteroscopy [7].

The limitation with transvaginal scan is incomplete visualisation of endometrial cavity in few women [8]. Saline infusion sonography is also helpful in identifying the uterine anomalies which can cause subfertility and recurrent pregnancy loss [8].

\section{Conclusion}

Saline infusion sonography, being an outpatient procedure requiring no anaesthesia and cost effective, can be used confidently to study the endometrial cavity in women with infertility. Those in whom abnormalities identified during the study can be taken up for invasive procedure, hysteroscopy. SIS can thus be performed as a preliminary procedure before hysteroscopy.

\section{Funding:Nil. Conflict of interest: Nil. Permission for IRB: Yes}

Abbreviations: TVS- Trans Vaginal Sonography, SIS - Saline Infusion Sonography

\section{References}

1. Blumenfeld Z, Yoffe N, Bronshtein M. Transvaginal sonography in infertility and assisted reproduction. Obstet Gynecol Surv. 1991 Jan;46(1):36-49.

\section{Allison SJ, Horrow MM, Kim HY, Lev-Toaff AS.} saline-infused sonohysterography: tips for achieving greater success. Radiographics. 2011 NovDec;31(7):1991-2004. doi: 10.1148/rg.317115074.

3. Berridge DL, Winter TC. Saline infusion sonohysterography: technique, indications, and imaging findings. J Ultrasound Med. 2004 Jan;23(1):97-112; quiz 114-5.

\section{Reddi Rani P1, Lakshmikantha G2,}

TransvaginalSonography (TVS) and Saline Infusion Sonohysterography (SIS) in the Evaluation of Abnormal Uterine Bleeding (AUB), J ObstetGynecol India Vol. 60, No. 6 : November / December 2010 pg $511-515$.

5. Nanda S, Chadha N, Sen J, Sangwan K. Transvaginal sonography and saline infusion sonohysterography in the evaluation of abnormal uterine bleeding. Aust N Z J Obstet Gynaecol. 2002 Nov;42(5):530-4.

6. Khan F, Jamaat S, Al-Jaroudi D. Saline infusion sonohysterography versus hysteroscopy for uterine cavity evaluation. Ann Saudi Med. 2011 JulAug;31(4):387-92. doi: 10.4103/0256-4947.83213.

7. Aslam M, Ijaz L, Tariq S, et al. Comparison of Transvaginal Sonography and Saline Contrast Sonohysterography in Women with Abnormal Uterine Bleeding: Correlation with Hysteroscopy and 
Histopathology. International Journal of Health Sciences. 2007;1(1):17-24.

8. Kelekci S, Kaya E, Alan M, Alan Y, Bilge

U, Mollamahmutoglu L. Comparison of transvaginal sonography, saline infusion sonography, and office hysteroscopy in reproductiveaged women with or without abnormal uterine bleeding. Fertil Steril. 2005 Sep;84(3):682-6.

\section{How to cite this article?}

Sripriya Thiruvengadathan, T.G. Sivaranjani, Vidya Chaya, Devi. Role of saline infusion sonography in patients with infertility and comparison of the same with transvaginal ultrasonography. Int J Med Res Rev 2015;3(11):1322-1326. doi: 10.17511/ijmrr.2015.i11.240. 